\title{
Uniqueness-Seeking Behaviour and Innovativeness of Young Consumers: Perspectives on South African Fashion Designer Labels
}

\author{
Nobukhosi Dlodlo \\ Lecturer: Department of Marketing Management \\ Faculty of Management Sciences, Vaal University of Technology \\ Private Bag X021, Vanderbijpark, 1900, South Africa \\ Email:nobukhosid@vut.ac.za; khosidlodlo@hotmail.com
}

Doi:10.5901/mjss.2014.v5n15p191

\begin{abstract}
The purpose of this study was to establish the underlying dimensions for students' need for uniqueness and further validate the relationship with fashion innovativeness with regard to South African based designer labels. A survey was conducted by use of a self-administered questionnaire on a random sample of 203 university students in a university situated in Southern Gauteng, South Africa. High cronbach alpha values $(\alpha<0.70)$ for all the sub-scales corroborated the internal consistency of the scale that was used in the current study. In addition, moderate to strong correlation coefficients were established between creative choice $(p<0.01)$, unpopular choice $(p<0.05)$ and similarity avoidance $(p<0.05)$ with fashion innovativeness. In addition, statistically significant results were obtained on the linear regression procedure between the creative choice counter-conformity dimension $(p<0.01)$ as well as the similarity avoidance dimension $(p<0.05)$ with fashion innovativeness. However, no predictive validity was established along the unpopular choice dimension ( $p>0.05)$. The results of the study provide a signal to managers in the fashion industry that greater focus should be placed upon designing unique designer offerings in order to satiate the propensities of innovative consumers. Such consumers express clear needs that are different from those of the masses and it is thus the task of the manager to respond dynamically to such fashion expectations. The study is significant in that it adds to the knowledge base regarding recent growth of new clothing designer labels which have been established by South African entrepreneurs as the hallmark of a Pan-African fashion style.
\end{abstract}

Keywords: Fashion innovativeness, need for uniqueness, designer labels

\section{Introduction}

In South Africa, the proliferation of black designers and design houses can be understood in relation to debates around black economic empowerment coupled with restructuring trends in the local clothing industry (Christianson, 2004). Relatedly, fashion is part of an important industry in South Africa, one which is heavily supported by fiscal authorities as part of their economic development programme. The local retail clothing industry's turnover was estimated at approximately R50 billion per annum a decade ago (Makholwa, 2010) and experienced a compounded 8.3 percent annual growth rate between 2004-2010 (Research and Markets, 2010). It is thus recognised that the future prosperity of the local clothing economy lies in value-added designs and manufacturing around certain niche products and markets which are viewed as having long term potential to penetrate specialist local, regional and international markets. At the heart of this is the repositioning of the local clothing economy and the encouragement of new African designs and apparel. Indeed, as stated by Barnes (2004) in the sector policy overview of clothing, in order to enhance competitiveness of the industry, considerable emphasis should be placed on the need to develop proudly South African designer labels.

The clothing industry is classifiable as a subdivision of the larger fashion industry within a business context. Fashion industry in a broad context is used to define all the manufacturing processes involved in making accessories, clothing, footwear, active wear, fashion apparel and bags (Makholwa, 2010). This study acknowledges the existence of diverse manufacturing disciplines within the broader fashion industry, but in the interest of simplifying the research process, focus was placed exclusively on proudly South African (original) branded clothing. In addition, given the evidence that innovativeness is domain specific, a decision was made to focus on South African fashion designer labels as the domain of interest for this study. Furthermore, fashion (specifically clothing) is seen as very relevant because of its symbolic properties and accessibility to a majority of consumers. Accordingly, a report by the Design Indaba expo (2013), identified the best performing designer labels founded by local South African entrepreneurs to be inter alia; Black coffee, Rubicon, Missshape, Suzane Heyns, Naked Ape, Installations, Loxion Kulca, Erre and Stoned Cherrie. These designer 
labels are known to evoke uniqueness and exclusivity, as interpreted through high product quality (Ling, 2009), psychological value (Latter, Phau \& Marchegiani, 2010), highly involved consumption experiences (Latter, 2012), controlled distribution and premium pricing (Ruvio, 2008).

\subsection{Fashion innovativeness}

Fashion innovativeness is the degree to which a person is interested in trying new brands, products and stores (Jordaan \& Simpson, 2006). However, this level of innovativeness is domain specific, which means that consumers tend to be innovators for a specific product or product category (Goldsmith \& Newell, 1997; Muzinich et al., 2003). Therefore, innovative behaviour cannot be generalized. This is because one may find that consumers who are likely to adopt the latest product in one field may be laggards in another (Goldsmith et al, 1998).

However, given the conspicuous nature of clothing and its value in communicating identity, another important concept linked to fashion consciousness and fashion innovation is the need for uniqueness (Park, Rabolt \& Jeon, 2008). Individuals with a low need for uniqueness are likely to select products, including clothing, that conforms with the expectations of their significant others, whereas, those with a high need for uniqueness are more likely to express themselves, including with clothing, through unique choices (Schiffman, Kanuk \& Wienblit, 2010).

\section{Underlying Theoretical Contexts}

The research questions that were posed in the study were addressed by the need for uniqueness (NFU) theory (Snyder, 1992; Snyder \& Fromkin, 1977) and the consumers' need for uniqueness (CNFU) construct that evolved from it (Tian, Bearden, \& Hunter, 2001). According to the NFU theory, all individuals crave uniqueness to some extent. On one hand, some people desire to be just like everybody else (low NFU) whilst on the other, people want to be as different and distinct as possible (high NFU). Given that possessions are often perceived as part of the "extended self, one form of the expression of individuality and uniqueness is through the selection and use of products and brands. As such, enriching a consumer's self-image through fashion-related products is an internal, subjective process and will occur if the consumer sees the product as having symbolic meaning, as well as symbolic public importance.

Tian et al. (2001:52) defined CNFU as 'the trait of pursuing differences relative to others through the acquisition, utilization and disposition of consumer goods for the purpose of developing and enhancing one's self-image and social image'. Market mavens and product innovators are the example of the consumers from this group. These consumers are branding conscious because of their tendency to fulfil their needs for unique features, exclusivity and prestige look (Solomon \& Rabolt, 2004). Accordingly, the CNFU construct utilizes three dimensions of consumption behaviour to capture how people fulfil their need for uniqueness: creative choice counter-conformity, unpopular choice counterconformity, and avoidance of similarity (Tian \& McKenzie, 2001). The CNFU concept is thus an application of the NFU albeit, in the consumer behaviour context. Therefore, the current study posits that need for uniqueness is a universal need amongst individuals across different cultures and therefore, plays a pivotal role towards shaping the psychological motives for consumer behaviour and consumption choices. Thus, people use affective and behavioural mechanisms to maintain moderate levels of similarity (or dissimilarity thereof) to others. The extent to which these mechanisms are used depends on the strength of individuals' NFU. For example, high NFU increases individuals' sensitivity to similarity and the ensuing desire to differ from others (Snyder, 1992). However, this desire is constrained by the need for social approval (Snyder \& Fromkin, 1977). As such, individuals in search of uniqueness will tend to exhibit it in a positive manner and avoid displays that might evoke social sanctions from the public.

\subsection{The relationship between consumers' need for uniqueness and fashion innovativeness}

Fromkin (in Roehrich, 2002) was the first to suggest a link between innovativeness and the need for uniqueness. According to Fromkin, the need for uniqueness pushes the individual to distinguish himself/herself through the possession of rare items. Snyder and Fromkin (in Roehrich, 2002) suggest three consequences of the need for uniqueness: the absence of interest in the reaction of others to one's own different ideas or acts; the desire to break away from following the rules; and the willingness to publicly defend one's unusual opinions. The external expression of an individual's need for uniqueness, which is the outcome of a social comparison process, depends on the individual's selfperceived degree of uniqueness relative to others. Through this social comparison process, individuals compare themselves with others (groups or individuals), thereby providing themselves with a frame of reference within which future decision-making behaviour can occur. 
Burns and Krampf in Roehrich (2002) observed that individuals with high needs for uniqueness were more apt to adopt new products than were individuals with low needs for uniqueness. The need for uniqueness is therefore a credible antecedent of innovativeness. Firstly, because innovativeness is an easy way to satisfy the need for uniqueness and secondly, because the need for uniqueness includes independence in judgement, which is necessary for innovative purchasing (Roehrich, 2002). The need for uniqueness may manifest in the buying of fashionable clothing. If individuals perceive themselves as having insufficient personal uniqueness, they will be prompted to pursue activities such as buying fashionable clothing by designer labels, which may have the potential to rectify this undesirable situation. Furthermore, individuals with stronger needs for uniqueness would be more likely to desire consumer choices which may be viewed as non-traditional, such as buying new fashion clothing from a channel through which the need for uniqueness can be manifested.

The need to be different is often an individual's motivation to counter conformance to societal norms. This deviation from the norm is viewed as an avenue for individuals to enhance their self-concepts through the utilisation of fashion clothing and possessions, especially those deemed scarce or rare (Tian et al., 2001; Snyder \& Fromkin, 1977). Since designer labels are inherently scarce due to their high price and restricted distribution, they can become a tool to convey uniqueness (Bian \& Forsythe, 2011). Previous research findings indicate that CNFU variables are positively correlated with domain innovativeness (Goldsmith et al, 1998; Roehrich, 2002). These variables, namely creative choice counterconformity, unpopular choice counter-conformity and similarity avoidance are discussed below within the context of South African designer labels.

Creative choice counter-conformity refers to individuals' ability to use products in creating personal styles and expressing self-images in a way that is viewed as socially acceptable (Tian et al., 2001). From a fashion perspective, the consumers have a tendency to select the clothing items that are creative, prestigious and unique (designer wear) yet still socially acceptable. Creative choices are manifested by consumption selections that are likely to be valued as unique and approved by others in one's social contexts, leading to a positive social evaluation (Snyder \& Fromkin, 1977). Studies of Solomon and Rabolt (2004) suggest that such consumers are brand conscious because of their tendency to fulfil their needs for unique features, exclusivity and a prestigious look. Invariably so, this characteristic renders them innovators in specific product categories.

Unpopular choice counter-conformity refers to consumers' use of products deviating from social norms to some extent. They usually do not attend to people's criticism and tend to make decisions to purchase goods that others might consider odd and unusual (Simonson \& Nowlis, 2000). Consumers from this group prefer to make selections of products that are different from social norms and can increase their self-image. Additionally, an unpopular and norm-breaking consumption behaviour in the present may gain social approval over time, and mark the consumer as an innovator or fashion leader (Heckert, 1989). Individuals in search of differentiation from others avoid buying and consuming commonly used products and brands. Such individuals lose interest in, avoid purchasing, or discontinue using those brands when they become common.

Finally, avoidance of similarity implies an effort to avoid using widely adopted fashion products or mainstream brands. It causes consumers to avoid buying or discontinue using products or designer labels once they become diffused (Latter, 2012). Since, a unique image is considered desirable; the more powerful it is, the greater the individual's sensitivity to conformity and the more different from others he or she will want to be. These consumers tend to choose products that are not too popular at a particular point in time (Knight \& Kim, 2007). Other than that, they also have the tendency to develop innovative strategies to make their fashion look different from others, for instance, they might come out with a unique combination of apparel, unique colour blocking or shop only at vintage stores (Simonson \& Nowlis, 2000). Therefore, it may be concluded that the avoidance of similarity may be a breeding ground for consumer innovativeness.

\section{Problem Investigated}

The study of uniqueness on replacement behaviours can be applied to the fashion industry; primarily the branded clothing spectrum where trends and styles are ever-changing. Many previous studies on fashion consumption, consumers' need for uniqueness and status consumption have been conducted on a predominately Asian or a European sample (Bian \& Forsythe 2011; Kumar, Kim, \& Pelton 2009; Park, Rabolt \& Jeon 2008; Ruvio, Shoham \& Brencic, 2008; O' Cass \& Choy, 2008; Knight \& Kim 2007). Few studies have been conducted using an Australian sample (e.g. Latter, 2012) and an even scant proliferation of studies have been observed within the African context (e.g. Bevan-Dye, Garnett \& De Klerk, 2012; Jordaan \& Simpson, 2006). Notwithstanding this fact, it is thought-provoking to establish that most of the previous studies on the outcome variables associated with CNFU have not linked need for uniqueness with fashion innovativeness within 
the context of the student population, as an active consumer group. As such the following research hypothesis are formulated for the study:

$H_{1}$ : There is a positive relationship between creative choice counter-conformity and fashion innovativeness

$\mathrm{H}_{2:}$ There is a positive relationship between unpopular choice counter-conformity and fashion innovativeness

$H_{3}$ : There is a positive relationship between similarity avoidance and fashion innovativeness.

Based on these hypotheses, the conceptual framework for the study is proposed on Figure 1.

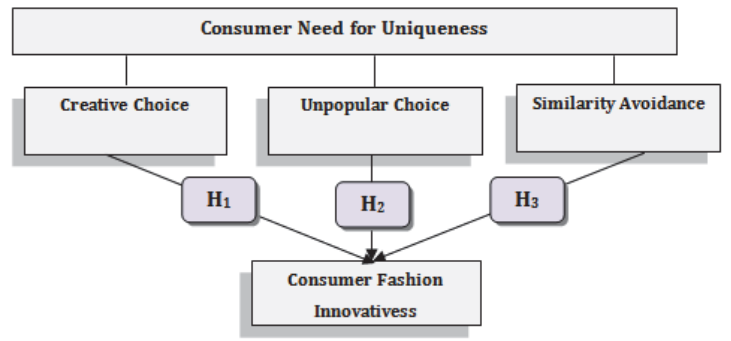

Figure 1: Conceptual framework

\section{Research Methodology}

A quantitative research design was followed in the study, through a self-administered survey instrument as this was necessary to examine the relationship between the constructs used in the study.

\subsection{Sample Participants}

The target population of the study consisted of tertiary students in the Southern Gauteng region. A student sample was chosen for a number of reasons. Firstly, there appears to be a connection between need for uniqueness, fashion innovativeness and the student community and evidence shows that this cohort is more concerned with beauty, appearance and fashion (Bian \& Forsythe 2011; Kumar et al., 2009). Secondly, as stated by Khoo and Conisbee (2008), young people are both lucrative and fickle and are set to dominate the retail trade sector in terms of their enormous spending power and strong interest in shopping. This invariably so renders the student community, a fashion conscious cohort that is likely to be innovators within the context of the fashion industry. Furthermore, the youth market offers an important target market for fashion and apparel marketers (Cassidy \& van Schijndel, 2011). In marketing speak, the youth market of the twenty-first century (also known as Generation Y) generally prefer brands with a certain level of identity, based on values with which they can identify and express their individuality. These brand perceptions are then driven by their unique own needs and brand knowledge stemming from their personal experiences.

\subsection{Item generation and measuring instrument}

The consumer need for uniqueness scale, short-form (CNFU - S) by Ruvio et al. (2008) was adapted in the current study based on its uni-dimensionality and cross-cultural invariance. This suggests that no cross-nation constraints were imposed; hence limited bias and errors may be expected as the scale attained cross-cultural equivalence. In addition high Cronbach alpha values were observed on the scale in the order of .770 to .94 to provide further support for the internal consistency of the scale in operationalization and development of cumulative research. Data were gathered using a structured self-administered questionnaire that was anchored on a seven-point Likert scale ranging from strongly disagree (1) to strongly agree (7). The CNFU scale incorporated the three sub-dimensions of creative choice counterconformity (4 items), unpopular choice counter-conformity (4 items) and similarity avoidance (4 items).

In addition, the outcome variable; consumer fashion innovativeness was adapted from the Domain Specific Innovativeness Scale (DSI) of Goldsmith et al., (1998). This is a balanced scale with three positively and three negatively worded items. Several studies have shown the DSI to be reliable (between .81 $a \leq .86$ ), valid and free from social desirability bias (Bearden et al, 1993). The wording of the scale items was adapted to make them appropriate to a fashion context. A section on the demographic profile of the respondents was included in the questionnaire with variables relating to the gender, age, ethnic group, education levels and brand preferences (by ranking) of the participants. These questions were structured on dichotomous, multiple choice and ranking-order closed-ended scales, respectively. 


\subsection{Data collection procedure}

A quantitative approach was adopted in which 400 questionnaires were distributed to a randomly selected sample of university students with permission from lecturers approximately 20 minutes prior to the end of class sessions. The survey site was based in the Southern Gauteng Province of South Africa and data were collected at different times and days of the week, to ensure randomisation. A simple random sampling procedure was employed to collect data from a sample as it allows every unit of analysis an equal chance of being included in the study (Malhotra, 2010). Three postgraduate students were identified as primary contacts at the university and were further provided with training; which enabled them to assume the role of research assistant/s by facilitating the data collection procedure. Informed consent was observed by utilising an accompanying letter and opening statements on the questionnaire, citing the purpose, nature and legitimacy of the study. In addition, respondents were assured that the information they provided would be strictly used for research purposes only and their identities would remain anonymous at all times. Voluntary participation was encouraged and the respondents were informed that they were able to withdraw from the study if they wished to do so.

Out of the 400 questionnaires that were distributed, 287 questionnaires were returned. Among these, 85 questionnaires were discarded because of non-compliance with the set age parameters (between 18 to 35 years), incorrect completion of questionnaire or too many fields of data missing. This culminated in an eventual sample of 203 usable questionnaires, giving a response rate of $51 \%$.

\subsection{Reliability and validity of the study}

Since the CNFU scale was adapted from previous studies, it was necessary therefore, to verify the internal consistency (reliability) and uni-dimensionality of the scale. According to Malhotra (2010), Cronbach's alpha values between 0.60 and 0.69 are deemed acceptable whilst values above 0.70 are regarded as satisfactory. Individual coefficient alpha values for the subscales ranged between 0.780 and 0.863 as shown on Table 1. Additionally, the Cronbach alpha value for the entire scale was 0.869 revealing the internal consistency and homogeneity of the entire scale.

Table 1: Cronbach alpha values: CNFU dimensions and fashion innovativeness

\begin{tabular}{lccc}
\hline Dimension/Construct & N & Number of items & Cronbach Alpha \\
\hline Creativity Choice & 203 & 4 & 0.845 \\
Unpopular Choice & 203 & 4 & 0.851 \\
Similarity Avoidance & 203 & 4 & 0.863 \\
Fashion Innovativeness & 203 & 5 & 0.780 \\
\hline \multicolumn{2}{l}{ Overall Cronbach Alpha for the entire scale $=0.869$} & & \\
\hline
\end{tabular}

Face validity was assessed through a debriefing exercise with a consumer behaviour scholar, culminating into the subsequent procedure of re-arranging the layout and sequencing of statements on the questionnaire. In addition, a pretest survey with a conveniently selected sample of 40 respondents revealed high inter-factor correlations ranging between .587 and .716 at both $p<.01$ and $p<.05$ levels. In line with the studies of Jordaan and Simpson (2006) as well as Latter (2012), the significant inter-factor correlations reported in this study provide justification on the clinical utility of the scale that was used in the current study. However, as a precautionary measure, the 40 pilot-respondents were excluded from the main survey to avoid sampling bias.

Convergent validity was assessed through a computation of Pearson correlation coefficients. Strong, positive and significant correlations were established on the three dimensions underlying the CNFU variable, providing evidence of convergence. Similarly, the high alpha values on the scale items $(\geq 0.70)$ reflect the degree of cohesiveness among the scale items serving as an indirect indicator of convergent validity (Nunnally \& Bernstein, 1994). Predictive validity was assessed through regression analysis whereby the three CNFU dimensions, namely; creative choice, unpopular choice and similarity avoidance explained approximately $53 \%$ of variance in the fashion innovativeness variable.

\section{Data Analysis}

Descriptive and inferential statistical analyses were assessed using the Statistical Package of the Social Sciences (SPSS version 21.0). 


\subsection{Demographic Profile}

The sample composition indicate that there were less male respondents $(n=73 ; 36 \%)$ as compared to the females $(n=130 ; 64 \%)$. It is important to note that in past studies females accounted for a higher percentage in terms of fashionrelated studies (Ruvio et al., 2008; Ruvio, 2008; Jordaan \& Simpson, 2006). Majority of the respondents ( $\mathrm{n}=97 ; 48 \%$ ) were between 18 and 23 years of age, followed by the age groups, 24 to 29 years $(n=75 ; 37 \%)$ and 30 to 35 years $(n=31$; $15 \%)$ age groups, respectively. Majority of the respondents were black majority ( $n=187 ; 92 \%)$ in terms of racial composition of the sample and this is representative of the ethnic distribution among students at the survey site. In addition, a larger proportion of the sample comprised of undergraduate students ( $n=163 ; 80 \%)$.

\section{Results and Discussion}

Pearson correlation analysis was used to establish the possible existence of a relationship among the sub-scales. This procedure is applied with a view to assess the degree to which quantitative variables are linearly related in a sample. These results are reported on Table 2.

Table 2: Correlation analysis: CNFU dimensions versus fashion innovativeness

\begin{tabular}{|l|c|c|c|c|}
\hline Dimension & Creative Choice & Unpopular choice & Similarity avoidance & Fashion innovativeness \\
\hline Creativity Choice & 1 & & & $.493^{* *}$ \\
\hline Unpopular Choice & $.171^{*}$ & 1 & 1 & $.363^{*}$ \\
\hline Similarity Avoidance & .030 & $.267^{*}$ & $.194^{*}$ \\
\hline Fashion Innovativeness & $.493^{* *}$ & $.363^{*}$ & 4.102 & 1 \\
\hline Mean $(\bar{x})$ & 4.446 & 3.625 & 1.637 & 3.991 \\
\hline Standard deviation & 1.198 & 1.049 & 1.528 \\
\hline
\end{tabular}

The results of the correlation matrix reveal that there were positive and significant relationships among the three uniqueness-seeking variables with fashion innovativeness $(0.194 \leq r \leq 0.493)$ at both the $p<0.01$ and $p<0.05$ levels. This suggests that an increase in creativity counter-conformity as well as unpopular choice counter-conformity will invariably lead to enhanced originality and innovativeness regarding designer brands. In addition, consumers seeking similarity avoidance have higher propensity for innovative behavior and originality when it comes to fashion brands and dress sense.

Since the relationship between the CNFU dimensions showed positive correlations with fashion innovativeness, there was need to perform stringent inferential statistics. Linear regression analysis was conducted with a view to corroborate the existence of a predictive relationship between the predictors (CNFU dimensions) and their relative measurement response (fashion innovativeness). Initially, however, the assumptions of the regression models along with co-linearity diagnostics' checks were ascertained. Firstly, the correlation matrix was examined for existence of multi colinearity, i.e. if the predictor variables correlates too highly $(r>0.9)$ with each other (Field, 2005). None of the correlations in Table 2 reached a value of $>0.9$ hence the data was considered suitable for linear regression analysis using the enter method. VIF values were 1.215 (creative choice), 1.829 (unpopular choice) and 3.412 (similarity avoidance), which is considered acceptable as it is within the suggested threshold (1.000 $\leq \mathrm{VIF} \leq 10.000)$ as recommended by Malhotra (2010). Moreover, tolerance levels that fall below 0.1 indicate serious co-linearity problems whereas those tolerance values that are below 0.2 may potentially cause co-linearity problems. Inspection of the model results suggests that't' statistics for the predictor variables ranged from 4.297 to 6.309 inferring that there was no co-linearity within the data set. The results are presented in Table 3. 
Table 3: Regression Model - CNFU factors and innovativeness

\begin{tabular}{|c|c|c|c|c|c|}
\hline \multirow{3}{*}{$\begin{array}{l}\text { Independent variables: Consumer } \\
\text { Need for uniqueness }\end{array}$} & \multicolumn{5}{|c|}{ Dependent variable: Fashion innovativeness } \\
\hline & \multirow{2}{*}{$\frac{\text { Standardised Coefficients }}{\text { Beta }}$} & \multirow[b]{2}{*}{$\mathrm{t}$} & \multirow{2}{*}{ Sig. } & \multicolumn{2}{|c|}{ Collinearity Statistics } \\
\hline & & & & Tolerance & VIF \\
\hline Creativity Choice & .879 & 4.297 & .003 & .571 & 1.215 \\
\hline Unpopular Choice & .261 & 4.801 & .217 & .682 & 1.829 \\
\hline Similarity Avoidance & .103 & 6.309 & .046 & .595 & 3.412 \\
\hline
\end{tabular}

The three factors accounted for approximately $39 \%\left(R^{2}=0.623\right)$ of the variance explained in fashion innovativeness. Colleniarity statistics for the five extrinsic motivation factors were within acceptable values, indicating that multi-co linearity was not a problem in the present study as the independent variables were not highly correlated. Furthermore, a large F statistic was obtained on the regression model at a value of $28.727(p=0.000)$ thus confirming the fitness of the regression model in measuring the predictive relationship between the CNFU dimension with fashion innovativeness.

Strong and positive correlation coefficients were observed between the creative choice dimension with innovativeness $(r=0.493 ; p<0.01)$. In addition, this dimension was ranked first on the CNFU factor mean score rankings ( $\bar{x}=4.446 ; \mathrm{SD}=1.198$ ) providing some indications of the encouraging level of agreeability regarding the role of creative choice on the consumers' decisions to be innovative in their fashion decisions. Moreover, the results of the regression analysis also reveal that creative choice is a statistically significant predictor of consumers' fashion innovativess $(\beta=$ $0.879 ; t=4.297 ; p<0.01)$. Hence, the null hypothesis is rejected in favour of $\mathrm{H}_{1}$ which states that creative choice counterconformity is positively related to consumer fashion innovativeness is therefore supported. This suggests that consumers that have high creativity choice have a need to express their uniqueness but at the same time want to be considered as fashion experts, by their peers (Latter, 2012; Jordaan \& Simpson, 2006). They are more likely to perceive the South African fashion brands as high quality, reputable and prestigious. This shows that brands with a great value and image are important in expressing their uniqueness and individuality; ultimately leading to innovative behaviour. Therefore, as part of CNFU, creative choice counter-conformity should be appreciated in an individualistic culture such as South Africa, since uniqueness is one of the hallmarks of individualism.

In terms of the unpopular choice dimension, moderate but positive correlation coefficients were observed with consumers' fashion innovativeness $(r=0.363 ; p<0.05)$. This dimension was ranked third $(\bar{x}=3.625 ; \mathrm{SD}=1.049)$ on the factor mean score rankings indicating that there was limited consonance among the respondents, regarding the importance of unpopular fashion choices that are aimed at demonstrating originality. It is interesting to note that the results of the current study revealed that unpopular choice is not a statistically significant predictor of fashion innovativeness ( $\beta=0.261 ; t=4.801 ; p>0.05$ ). Hence $\mathrm{H}_{2}$ which states that unpopular choice counter-conformity is positively related to consumer fashion innovativeness is therefore rejected. These findings are in unison with studies of Latter et al. (2010) as well as Ruvio (2008) who asserted that there is no direct, predictive relationship between unpopular choices with fashion innovativeness among consumers. The results of the study substantiate the notion that a majority of consumers in South Africa operate within a social system and therefore their choice of uniqueness has to comply with social norms. That means, they are conscious of the commendations of their peers and therefore, in their fashion innovativeness, avoid wearing clothing items that would cause social risk to their egos (Muzunich et al., 2003). After all, most consumers do not want to seek fashion-related advice from consumers who purchase only deviant products and always run counter to popular product choices.

Regarding the similarity avoidance dimension, moderate and positive correlation coefficients were observed with the fashion innovativeness variable $(r=0.194 ; p<0.05)$. Nonetheless, this dimension was ranked second on the CNFU mean factor scores $(\bar{x}=4.102$; $\mathrm{SD}=1.637)$ indicating that a majority of the respondents considered this dimensions to be very important in determining the level with which they are able to express their fashion uniqueness. Furthermore, the results of the regression analysis revealed that similarity avoidance was a statistically significant predictor of consumers' fashion innovativeness $(\beta=.103 ; t=6.309 ; p<0.05)$. Hence $\mathrm{H}_{3}$ which states that similarity avoidance is positively related to consumer fashion innovativeness is therefore supported. These findings are contrary to the studies of Ryan (2008) who tested the efficacy of the consumers' need for uniqueness scale and conceded that similarity avoidance has limited salience in relation to the various dimension that augment causality with fashion innovativeness, among consumers. This finding can be explored further with a view to corroborate the significance of this predictor variable towards fashion innovativeness and opinion leadership behaviour, using different samples. 


\section{Strengths, Limitations and Future Directions}

Fashion clothing has important economic and social significance in many societies and should be a focus of many more studies. It is within the same vein that the findings of the study constitute an important source of knowledge and information on the antecedents of need for uniqueness dimensions within the context of South African young consumers. However, the study has a limitation in that its results are restricted to a small sample size (203 respondents) situated in only one province in South Africa. In addition, the study was limited to one metropolitan university and generalisations were only made based on the top ten local apparel brands or designer labels. Therefore, the results may not be precise for other geographical areas nor are they generalizable within the context of global brands. It may be interesting to conduct studies on specific local designer labels or extend scholarship to include comparison perspectives of the consumers' purchase intentions towards international brands versus local brands. Ryan (2008) further advocates for gender-sensitive studies focusing on uniqueness seeking across diverse cultures. Consumer need for uniqueness may be considered when developing merchandising and marketing strategies for various consumer cohorts in both domestic and international markets. However, future research should systematically extend the approach by profiling fashion innovators. There is also a need to investigate relationships among innovativeness and other constructs of interest, such as media usage and brand sensitivity.

\section{Conclusions and Managerial Implications}

Since material goods; in particular, fashion designer labels are identified as a good form of demonstrating differentiation, consumers' need for uniqueness has slowly gained popularity as a topic in the marketing discipline. The consumption patterns of consumers' with varying degrees of uniqueness has been widely studied and applied to a number of consumer goods with the exclusion of local designer labels with a pan African style. The results of this study will enable fashion houses and managers to see if South African based designer labels effectively target consumers with uniqueness-seeking attributed with a view to enhance their innovativeness. The identified dimensions; creative choice, similarity avoidance and unpopular choice are respectively important for respondents who have a desire to express their individuality while maintaining social norms. Therefore, managers in the fashion industry should attempt to create awareness among young innovators through unique labels, exclusive shopping avenues and advertising etc. because other consumers turn to them for advice regarding the latest fashion trends.

\section{References}

Barnes, J. (2004). A Strategic Assessment of the South African Wearing Apparel Sector. Unpublished report for the Trade and Industrial Policy Strategies, Johannesburg.

Bearden, W., Netemeyer, R. G. \& Mobley, M. F. (1993). Handbook of marketing scales. Newbury Park. SAGE Publications.

Bevan-Dye, A. L., Garnett, A. \& Klerk de. N. (2012). Materialism, status consumption and consumer ethnocentrism amongst black generation Y students in South Africa. African Journal of Business Management, 6(16), 5578-5586.

Bian, Q. \& Forsythe, S. (2011). Purchase intention for luxury brands: A cross cultural comparison. Journal of Business Research, 65(10), 1443-1451.

Cassidy, T. D. \& Van Schijndel, H. (2011). Youth identity ownership from a fashion marketing perspective. Journal of Fashion Marketing and Management, 15(2), 163-177.

Christianson, D. (2004). BEE 10 Years On. Enterprise Report, 186 (April, 2004), 104-108.

Design Indaba Expo report (South Africa) (2013). [Online] Available: http://www.designindaba.com/events/fashion-shows-expo-2013. (January, 26 2014)

Goldsmith, R. E., Moore, M. A. \& Beaudion, P. (1998). The self-concept of fashion leaders. Clothing and Textiles Research Journal, 14, 242-248.

Goldsmith, R. E. \& Newell, S. J. (1997). Innovativeness and price sensitivity: managerial, theoretical and methodological issues, Journal of Product and Brand Management, 6(3), 163-174.

Heckert, D. M. (1989). The relativity of positive deviance: The case of the French Impressionists. Deviant Behaviour, 10, 131-144.

Jordaan, Y. \& Simpson, M. N. (2006). Consumer innovativeness among females in specific fashion stores in the Menlyn shopping centre. Journal of Family Ecology and Consumer Sciences, 34(1), 33-40.

Khoo, M. \& Conisbee, N. (2008). YTopia- Capturing Retailers' Paradise. Jones Lang LaSalle.

Knight, D. K. \& Kim, E. Y. (2007). Japanese consumers' need for uniqueness: Effects on brand perceptions and purchase intention. Journal of Fashion Marketing and Management, 11(2), 270-280.

Kumar, A. Kim, Y.-K. \& Pelton, L. (2009). Indian consumers' purchase behaviour towards US versus local brands. International Journal of Retail and Distribution Management, 37(6), 510-526. 
Latter, C. R. (2012). Status consumption and uniqueness: effects on brand judgement and purchase intention. M.Phil. Curtin University, Curtin Business School, School of Marketing: Australia.

Latter, C., Phau, I., \& Marchegiani, C. (2010). The roles of consumers' need for uniqueness and status consumption in haute couture luxury brands. Journal of Global Fashion Marketing, 1(4), 205-213.

Ling, G. (2009). Understanding consumer purchasing behaviour regarding luxury fashion related goods in China. (Doctoral dissertation). Retrieved from ProQuest Database.

Makholwa, A. (2010). Which retail model rules? Fin24.com, June 27. [Online] Available: http://www.fin24.com. (April, 6 2014)

Malhotra, N. K. (2010). Marketing research: an applied orientation. Eaglewood Cliffs, Prentice-Hall: NJ, USA.

Muzinich, N., Pecotich, A. \& Putrevy, S. (2003). A model of the antecedents and consequents of female fashion innovativeness. Journal of Retailing and Consumer Services, 1, 1-13.

Nunnally, J. C. \& Bernstein, I. H. (1994). Psychometric theory. McGraw-Hill.

O'Cass, A. \& Choy, E. (2008). Chinese generation Y consumers' involvement in fashion clothing. Journal of Product and Brand Management, 17(5), 341-352.

Park, H., Rabolt, N. J. \& Joon, K. S. (2008). Purchasing global luxury brands among young Korean consumers. Journal of Fashion Marketing Management, 12 (2), 244-259.

Research and Markets. (2010). Clothing: South African industry guide 2010. [Online] Available: http://www.researchandmarkets.com. (April, 6 2014)

Roehrich, G. (2002). Consumer innovativeness, concepts and measurements. Journal of Business Research, 1, 1-7.

Ruvio, A. (2008). Unique like everybody else? The dual role of consumers' need for uniqueness. Psychology and Marketing, 25(5), 444464.

Ruvio, A., Shoham, A. \& Makovec Brenc ic, M. (2008). Consumers' need for uniqueness: short-form scale development and crosscultural validation. International Marketing Review, 25(1), 33-53.

Ryan, H. Z. (2008). Uniqueness and innovativeness: A look at controversial men's fashion products, Curtin Business School, Curtin University of Technology, Perth.

Schiffman, L. G., Kanuk, L. L. \& Wisenblit, J. (2010). Consumer Behaviour. (10th ed). Upper Saddle River, NJ, USA: Pearson Prentice Hall.

Simonson, I. \& Nowlis, S. M. (2000). The role of explanations and need for uniqueness in consumer decision making: Unconventional choices based on reasons. Journal of Consumer Research, 27(1), 49-68.

Snyder, C.R. (1992). Product scarcity by need for uniqueness interaction: a consumer catch-22 carousel? Basic and Applied Social Psychology, 13(3), 9-24.

Snyder, C. R. \& Fromkin, H. L. (1977). Abnormality as a Positive Characteristic: The Development and Validation of a Scale Measuring Need for Uniqueness. Journal of Abnormal Psychology, 86, 518-527.

Solomon, M. R. \& Rabolt, N. J. (2004). Consumer behavior in fashion. Upper Saddle River, NJ: Prentice-Hall.

Tian, Kelly, T., Bearden, William, O. \& Hunter, Gary, L. (2001). Consumers' Need for Uniqueness: Scale Development and Validation. The Journal of Consumer Research, 28(1), 50-66.

Tian, K.T. and Mckenzie, K. (2001). The long-term predictive validity of consumers' need for uniqueness. Journal of Consumer Psychology, 10(3), 1971-1973. 